\title{
Em Tesê:
}

\section{A TENTAÇÃo POPULISTA SEGUE VIVA}

The Populist Temptation is Still Alive

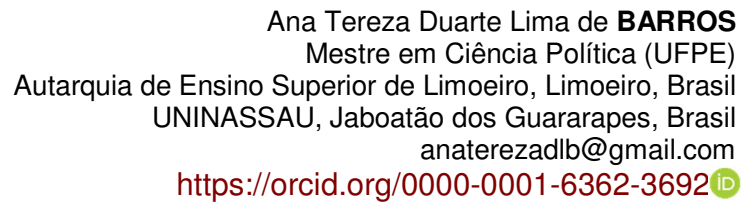

A lista completa com informações dos autores está no final do artigo

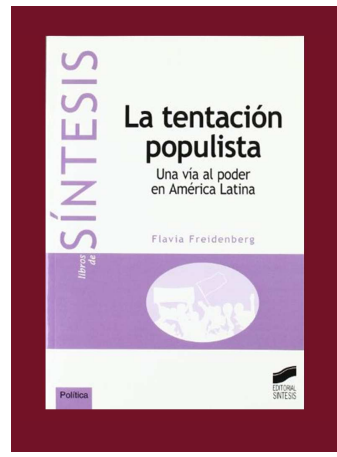

FREIDENBERG, Flavia. La tentación populista. Una vía al poder en América Latina. Madrid: Editorial Síntesis, 2007.

PALAVRAS-CHAVE: Populismo. Poder. América Latina. KEYWORDS: Populism. Power. Latin America. 
Com a ascensão ao poder de Donald Trump, nos Estados Unidos; a reaparição de líderes ultranacionalistas, na Europa; e a possível candidatura do militar da reserva Jair Bolsonaro, no Brasil, o tema "populismo" se encontra em alta, sendo recorrente nas colunas de opinião dos grandes jornais, pelos quais se observa que cada autor parece possuir seu próprio conceito do que seja o populismo - o que também ocorre dentro das Ciências Sociais -, e a obra "La tentación populista. Una vía al poder en América Latina", da cientista política Flavia Freidenberg, trata da questão com maestria. Ainda que o libro tenha sido publicado em 2007, em 2018, com o aparecimento de novas lideranças populistas no cenário mundial, a temática do populismo se encontra em um de seus auges.

Freidenberg introduz os vinte e um capítulos (divididos em cinco partes) do livro abordando a importância que o populismo teve no período de redemocratização da América Latina (início da década de 90), assim como a forma antidemocrática como seus líderes governaram (a exemplo de Collor, no Brasil; e de Menem, na Argentina). Na parte um, a autora reconhece o caráter "camaleônico" do termo populismo, que pode significar um tipo de liderança política, um tipo de política, um projeto econômico, ou o apelo carismático de um líder às massas.

$\mathrm{Na}$ parte dois, Freidenberg propõe uma definição de populismo que se caracterizaria por

un estilo de liderazgo, caracterizado por la relación directa, carismática, personalista y paternalista entre líder-seguidor, que no reconoce mediaciones organizativas o institucionales, que habla en nombre del pueblo y potencia la oposición de éste a "los otros", donde los seguidores están convencidos de los métodos redistributivos y/o al intercambio clientelar que tienen con el líder (tanto material como simbólico), conseguirán mejorar su situación personal o la de su entorno (FREIDENBERG, 2007, p. 25).

Alguns dos regimes classificados como populistas por Freidenberg receberam outras nomenclaturas por parte de distintos autores (O'DONNELL, 1994; MAINWARING et al., 2001).

Segundo Freidenberg, os populistas neoliberais foram os que deram origem ao que O’Donnell (1994) chamou "democracia delegativa", um tipo de democracia cujos líderes creem que são os únicos capazes de salvar o seu país, ou seja, os únicos capazes de tomar qualquer decisão política (já que receberam delegação por parte dos cidadãos, mediante eleições), de maneira que o controle feito pelas outras instituições de poder constituiria um obstáculo a sua agenda política. Esse foi o caso, por exemplo, de Collor de 
Melo, no Brasil; de Menem, na Argentina; de Fujimori, no Peru; e de Bucaram Ortiz, no Equador.

Mainwaring, Brinks e Pérez-Liñán (2001) abarcam no conceito de "semidemocracia" aqueles regimes que não satisfazem de maneira integral aos quatro requisitos mínimos (segundo os autores) de uma democracia: eleições competitivas; direito ao voto; que as liberdades civis e os direitos políticos sejam protegidos, e que as autoridades governem de fato, estando os militares sujeitos ao controle civil. Os regimes da Bolívia, sob o governo de Morales; e do Equador, sob o governo de Correa, podem ser considerados tanto democracias populistas, como o faz Freidenberg, como também exemplos de semidemocracias.

De fato, uma classificação dicotômica (democracia ou autoritarismo) seria incompatível com a realidade latino-americana, em que vários países se situam na zona da semidemocracia (BARROS; GOMES NETO, 2015).

Por outro lado, enquanto Chávez foi classificado por Freidenberg, em 2007, como líder de uma democracia populista, hoje a Venezuela se transformou em um tipo de "autoritarismo competitivo" (LEVITSKY; WAY, 2010; MAINWARING, 2012), uma vez que, ainda que as instituições democráticas formais existam, costumam ser controladas pelo Executivo. De igual maneira, as eleições são competitivas, contudo, a concorrência é injusta, posto que os políticas da situação logram obter vantagens (por exemplo, ao utilizar recursos de empresas estatais e controlar o acesso aos meios de comunicação), os partidos políticos de oposição são constantemente perseguidos e as liberdades civis e os direitos políticos, ainda que teoricamente garantidos, não são respeitados (BARROS; GOMES NETO, 2015).

A definição de Freidenberg de liderança populista é bem completa e útil para que se evite alguns equívocos. No Brasil, por exemplo, o presidente Lula foi, com frequência, considerado populista ou enquanto sinônimo de demagogo, ou pelo fato de seu programa de governo ser centrado em políticas públicas orientadas às classes mais populares, ou seja, aos mais desfavorecidos economicamente.

Segundo as definições de líder delegativo, de O'Donnell, e de líder populista, de Freidenberg, é possível compreender que o populista tenta passar por cima das instituições de poder, ou seja, um populista buscaria controlar os demais Poderes, incluindo o Judiciário. Dificilmente um líder populista se deixaria ser investigado pelo Ministério Público e posteriormente julgado por um tribunal (é o que aconteceu com Lula e dificilmente aconteceria com Maduro, por exemplo). 
Nas partes dois, três e quatro, Freidenberg analisa os casos específicos de alguns líderes latino-americanos que poderiam ser enquadrados como populistas. Em um primeiro momento se encontram os "velhos populistas", v.g. Getúlio Vargas, quem se utilizou do discurso direto às massas, exaltando suas qualidades pessoais e fazendo pouca referência a seu programa de governo. Em um segundo momento se encontram os "novos populistas neoliberais", v.g. Collor de Melo, no Brasil, que se apresentava como "a encarnação da nação" e "o defensor dos pobres", e que atuava à margem dos partidos políticos, dos sindicatos e demais organizações, incluídas as empresariais. Essa categoria criada pela autora é de especial importância, posto que o populismo é, com frequência, considerado um fenômeno exclusivo da esquerda. Mais recentemente, tiveram lugar as "expressões contemporâneas do populismo", estando aí incluídos Noboa, Chávez, Morales e Correa.

Em sintonia com a definição de populismo de Freidenberg se encontra o Novo Constitucionalismo Latino-americano, doutrina constitucional que surgiu na Venezuela e logo foi adotada no Equador e na Bolívia. Chávez, Correa e Morales, ao chegarem ao poder, trataram logo de convocar uma assembleia constituinte para redigir uma nova constituição. Ainda que a grande bandeira dessas constituições tenha sido a incorporação de novos direitos (sobretudo para a população indígena), os poderes legislativos do presidente foram consideravelmente aumentados, em especial o poder presidencial de convocar a população para plebiscitos e referendos, sendo essa característica plebiscitaria comum à maioria dos regimes de traço populista (BARROS, 2017).

Essa relação paternalista entre líder-seguidor, assim como a tentativa de dividir a sociedade em bandos, queda clara não só nos períodos populistas latino-americanos analisados por Freidenberg, mas também no tipo de liderança de Donald Trump, presidente dos Estados Unidos, quem, a cada dia, segrega mais a sociedade estadunidense (por exemplo, pondo os norte-americanos de origem europeia contra os norte-americanos de origem latina, africana ou asiática) e cujo discurso político quase sempre traz algum conteúdo de ódio, como ao propor a construção de um muro entre Estados Unidos e México. Em seu discurso inaugural, considerou sua chegada ao poder como sendo "o dia em que o povo se transformou de novo no governante da nação", ou seja, um discurso altamente delegativo e populista.

Nesse mesmo sentido, o atual presidente do Brasil, ex-deputado Federal e militar da reserva, Jair Bolsonaro, possui uma relação extremamente paternalista com seus simpatizantes, que o consideram o grande salvador da pátria e único capaz de acabar 
com a corrupção no Brasil. Muitos de seus seguidores o chamam afetivamente de "Bolsomito", como se ele fosse realmente um mito, um herói com superpoderes que os demais candidatos não possuíam, ainda que ele, com habitualidade, profira declarações antidemocráticas (a favor da tortura e das ditaduras militares, por exemplo), racistas, machistas e homofóbicas.

$\mathrm{Na}$ quinta e última parte de seu livro, Freidenberg compara as diversas experiências populistas e sublinha que, ainda que com políticas econômicas e bases de apoio distintas, todos os momentos populistas tiveram como denominador comum uma liderança política personalista, que dividiu a sociedade e desconsiderou a importância das organizações sociais e políticas. Conclui destacando que, se é verdade que uma maior participação das massas pode ampliar e fortalecer as estruturas democráticas, também pode provocar a transição do regime político a uma ditadura personalista.

\section{REFERÊNCIAS}

BARROS, Ana Tereza Duarte Lima de. A armadilha da democracia direta: uma análise qualitativa dos poderes legislativos do presidente na América do Sul. Dissertação em Ciência Política. Recife: Universidade Federal de Pernambuco, 2017.

BARROS, Ana Tereza Duarte Lima de; GOMES NETO, José Mario Wanderley. Liberalismo, republicanismo e democracia no marco do Novo Constitucionalismo Latinoamericano. Revista Eletrônica Direito e Política, v. 10, n. 4, p. 2146-2167, 2015.

FREIDENBERG, Flavia. La tentación populista. Una vía al poder en América Latina. Madrid: Editorial Síntesis, 2007.

LEVITSKY, Steven; WAY, Lucan. Competitive Authoritarianism. Hybrid regimes after the Cold War. Cambridge: Cambridge University Press, 2010.

MAINWARING, Scott. From representative democracy to participatory Competitive Authoritarian: Hugo Chávez and Venezuelan Politics. Perspective on Politics, v. 10, n. 4, p. 955-967, 2012.

MAINWARING, Scott; BRINKS, Daniel; PÉREZ-LIÑÁN, Aníbal. Classificando Regimes Políticos na América Latina. Dados, v. 44, n. 4, p. 645-687, 2001.

O'DONNELL, Guillermo. Democracia delegativa. Journal of Democracy, v. 5, n. 1, p. 723, 1994. 


\section{NOTAS}

\section{A TENTAÇÃO POPULISTA SEGUE VIVA}

Ana Tereza Duarte Lima de Barros

Mestre em Ciência Política (UFPE)

Autarquia de Ensino Superior de Limoeiro, Limoeiro, Brasil

UNINASSAU, Jaboatão dos Guararapes, Brasil

anaterezadlb@gmail.com

(D) https://orcid.org/0000-0001-6362-3692

\section{Endereço de correspondência do principal autor}

R. Pe. Carapuceiro, no 468, Ap. 104. CEP: 51020-280. Recife-PE, Brasil.

\section{LICENÇA DE USO}

Os autores cedem à Em Tese os direitos exclusivos de primeira publicação, com o trabalho simultaneamente licenciado sob a Licença Creative Commons Attribution Non-Comercial ShareAlike (CC BY-NC SA) 4.0 International. Esta licença permite que terceiros remixem, adaptem e criem a partir do trabalho publicado, desde que para fins não comerciais, atribuindo o devido crédito de autoria e publicação inicial neste periódico desde que adotem a mesma licença, compartilhar igual. Os autores têm autorização para assumir contratos adicionais separadamente, para distribuição não exclusiva da versão do trabalho publicada neste periódico (ex.: publicar em repositório institucional, em site pessoal, publicar uma tradução, ou como capítulo de livro), com reconhecimento de autoria e publicação inicial neste periódico, desde que para fins não comerciais e compartilhar com a mesma licença.

\section{PUBLISHER}

Universidade Federal de Santa Catarina. Programa de Pós-Graduação em Sociologia Política. Publicado no Portal de Periódicos UFSC. As ideias expressadas neste artigo são de responsabilidade de seus autores, não representando, necessariamente, a opinião dos editores ou da universidade.

\section{HISTÓRICO}

Recebido em: 20 de março de 2018

Aprovado em: 30 de julho de 2019 